A Study of Mother-Infant

Contact and Separation

Patterns in the Postpartum

Period and the Mother's

Perception of Her Infant

\title{
Mothers, Babies, Perception
}

Marilyn B. Lotas, R.N., M.S.N.

1979 Doctoral Student at University of Michigan and Instructor of Nursing. Oakland University, Rochester, Mich.

Judith M. Willging, R.N., M.S.N. Psychiatric Clinical Specialist, Veterans Administration Medical Center, Toledo Outpatient Clinic, Ann Arbor, Michigan.
Previous research findings suggest that there is a sensitive period immediately following the birth of a baby and that the contact between mother and baby is a significant variable in the development of the maternal caregiving activities. Based on this assumption, this study was undertaken to explore whether the increased infant contact which occurs in rooming-in situations is related to a more positive maternal perception of the baby. The mothers' perceptions of their babies were measured at two days and four weeks postpartum, using Broussard's Neonatal Perception Inventory. It was hypothesized that mothers in a rooming-in setting would demonstrate higher positive scores on the NPI at both observations than would mothers in a traditional setting. The study was carried out in the maternity units of three mid-western community hosptals, using samples of 46 rooming-in mothers and 35 mothers in a traditional setting. The findings did not support the hypotheses. Rather, the results suggest that mothers in a rooming-in setting tend to express more positive perceptions of their infants during their hospitalization than mothers in the traditional setting; however, the differences were not statistically significant. An additonal finding was that more prenatal education as well as participation in natural childbirth was positively correlated with more positive perceptions of the infant.

In recent years there has been increasing concern for the physical, emotional and social development of human infants. In particular, researchers are exploring the effects of variations in maternal caretaking on the child's subsequent emotional and physical development. Attention is being focused on the effects of such factors as the father's involvement with the mother in the birth process and the effects of mother-infant separation at various stages in the development of their relationship. The focus of this study was the relationship between patterns of postpartum contact and separation and mothers' perceptions of their babies. 


\section{Conceptual Framework}

Studies suggest the possibility of the existence of a sensitive period following the birth of a baby when the psychological and physiological status of the mother supports a high degree of receptivity to the baby and to the initiation of early caretaking behaviors. Early works with animals report the importance of contact between the animal mother and her young in the immediate neonatal period in that the baby's presence serves as a stimulation to the mother who then initiates and maintains maternal care-taking behaviors (Barnett \& Lieberman, 1970; Klaus, \& Kennell, 1976; Klopfer, 1971; Newton \& Newton, 1962; Rosenblatt, 1969; Terkel \& Rosenblatt, 1972; Zarrow, Gandleman \& Rosenberg, 1971). These studies report that separation of animal mothers from their infants in the immediate neonatal period has frequently resulted in deviant maternal behaviors ranging from failure to care for the young to actual physical attacks on the offspring.

Studies of human subjects also suggest the existence of a sensitive postpartum period for human mothers and their infants and demonstrate the importance of maternal-infant contact during this sensitive period for the early initiation of maternal caregiving activities (Barnett, Lieberman, Grabstein \& Klaus, 1970; Klaus \& Kennell, 1970; Klaus, Kennell, Plumb \& Zuehlke, 1970; Klaus, Jerauld, Kreger, McAlpine, Steffa \& Kennell, 1972; Leifer, Lieberman, Barnett \& Williams, 1972; McBryde, 1951).

An orderly progression of behaviors by which mothers begin to explore and become acquainted with their babies has been reported in a study comparing mothers of full-term infants with mothers of premature infants (Klaus, Kennell, Plumb \& Zuehlke, 1970). These behaviors are rapidly initiated when mothers have contact with their babies soon after birth. Mothers explore their infants beginning to touch the infants' extremities with their fingertips and progressing to palm contact with the infants' trunks. Much eye contact is also maintained during the physical exploration. By contrast, mothers of premature infants who have been separated from their infants for the first two to three postpartum days, explore their infants much more slowly than do mothers who have had early contact with their infants, although the pattern is the same.

McBryde (1951) notes that after the initiation of compulsory rooming-in, in which the amount of contact between mother and infant was greatly increased, breast feeding increased from 35 percent to 58.5 percent of the mothers. This suggests the possibility that increased contact between mother and infant in the postpartum period encourages caregiving activities such as breast feeding.

These studies suggest that a sensitive period may exist immediately following parturition in which contact between a mother and infant may influence the development of the maternal-infant relationship.

Human mothers and infants experience two predominant patterns of contact and separation in the early postpartum period: the pattern of the nursery-centered care, traditional since the early 1900's, and the pattern of rooming-in or family-centered care which has come increasingly into vogue since the 1960's. Early proponents of the nursery-centered infant have cited such advantages as the increased rest and relaxation for the mother and infection control due to the reduced access to the baby. Those in favor of the change to family-centered care argue that infection control is actually improved through the decentralization of infant care and further cite issues related to the psychological benefits to both mother and baby with increased contact (Baumann. 1950: Greenberg,
Rosenberg \& Lind, 1973; Jackson, 1946, 1948; Jackson, Olmsted, Foord, Thoms \& Hyder, 1948; Montgomery, Steward, \& Shenk, 1949; Parks, McLendon \& Kelley, 1953; Ringholtz \& Morris, 1961; Shea, Klatskin \& Jackson, 1952; Sonstegard \& Egan, 1976). Insufficient data have been collected to determine adequately whether these variations in the amount of contact of mothers and infants during this sensitive period postpartum resulted in significant alterations in maternal caregiving behaviors.

Broussard developed the Neonatal Perception Inventory (NPI) to compare the mother's perception of her baby and her perception of the average baby on six specific behaviors (Broussard, 1975, 1976; Broussard \& Hartner, 1970, 1971). These behaviors include the amount of crying, trouble in feeding, amount of spitting up, difficulty with sleeping, difficulty with bowel movements and trouble settling into a predictable pattern of eating and sleeping. Broussard, after administering the NPI at two days postpartum and at four weeks postpartum, reported that the NPI score obtained at four weeks postpartum was predictive of later problems in the child's emotional development as determined by independent therapists when the children were $4 \frac{1 / 2}{2}$ and 11 years of age.

The purpose of this project was to study the relationship between the mother's perception of her baby as measured by Broussard's NPI and differences in the amount of mother-infant contact as allowed by the hospital setting. An assumption of the study was that there is increased contact between mothers and infants in the rooming-in setting.

To accomplish the purpose of this study the investigators tested the hypothesis that: mothers who experienced a rooming-in setting postpartum will have higher positive scores on the NPI than mothers who experienced 
a traditional postpartum setting in which baby care took place primarily in the hospital nursery at a) two days postpartum and b) four weeks postpartum. Additional demographic and attributive data were collected during the study to determine the existence of any other variables which might affect the results.

\section{Method: Settings and Subjects}

Subjects for the study were selected from the maternity units of three metropolitan community hospitals in the Midwest. The initial contact with the mother took place during the mother's hospitalization on the first or second postpartum day. Additional contacts were made by a mailed questionnaire four weeks postpartum. The study sample consisted of one group " of 46 mothers who had a rooming-in arrangement with their babies and a second group of 35 mothers who experienced a traditional pattern of contact with their babies. The following criteria were established for mothers and infants to be included in the study: all mothers were married, free from chronic disease, had uncomplicated pregnancies, had labors that were no longer than 20 hours, delivered vaginally. Infants were fullterm, weighed at least $5-1 / 2$ pounds, had Apgar scores of at least seven within five minutes of birth, had no diagnosed medical problems or anomalies in the immediate postpartum period. All mothers meeting the criteria, whose hospitalization occurred during the 4-week data collection period, and who gave written informed consent to participate were included in the study. Both study groups included primiparae and multiparae. Rooming-in subjects were selected from the maternity units of two hospitals in which rooming-in was the established norm. These hospitals were from the same catchment area and were the major hospital maternity units available to mothers in that area. Non-rooming-in subjects were selected from the maternity unit of a hospital in which that was the established norm. Comparisons were made of the two sample groups from which the rooming-in sample was drawn to determine that no significant differences existed between the patient populations on such variables as occupational levels and educational backgrounds. Patient records were reviewed to determine those subjects who met the criteria for inclusion in the study.

\section{Method: Instruments}

Neonatal Perception Inventory (NPI). The NPI was developed by Elsie Broussard, M.D., and consists of two scales on which mothers are asked to rate the average baby and their own baby on six criteria: the amount of crying, trouble in feeding, amount of spitting up, difficulty in sleeping, difficulty with bowel movements and trouble settling into a predictable pattern of eating and sleeping. Each criterion is scored on a 5-point scale, ranging from "a great deal" ( 5 points) to "none" ( 1 point). The ratings on each scale are added separately, and the total from "Your Baby" is then subtracted from the "Average Baby" scale. This results in an NPI score, the possible range of which is from -24 to +24 . If a mother perceives her baby as having more difficulty on the six criteria than the average baby, the resultant NPI score will be negative and is considered to represent a negative maternal perception of her baby. If the mother rates her baby as having less difficulty than the average baby, the resultant NPI score will be positive and is considered to represent a positive perception of the infant. There are two forms of the NPI which differ only in the instructions on the "Your Baby" forms. The instructions for NPI I indicate that the mother has not yet had contact with the infant. The NPI II form instructions indicate that the mother has lived with her infant for four weeks. It is the NPI II score that is considered by Broussard to have predictive validity identifying children at high risk for problems with later emotional development (Broussard \& Hartner, 1970, 1971; Broussard, 1975). Broussard reports the NPI has both criterion and construct validity (Broussard \& Hartner, 1971).

General Information Questionnaire (GIQ). In order to explore whether selected additional variables may have affected the study results, an instrument was designed by the investigators to provide information about each subject's prenatal preparation, delivery experience, feeding method and preference for infant care arrangements during hospitalization. In addition, information was collected in regard to the age, parity, educational level of the mothers and the educational and occupational levels of the fathers. The father's occupational level was determined through the use of the Index of Social Characteristics Scale (Warner, 1960) which categorizes occupations on a seven-point ordinal scale.

\section{Method: Procedure}

The study required two observations of each study group. The first contact occurred in the hospital maternity unit one to two days postpartum. Subjects were given the General Information Questionnaire and the NPI I consisting of both the Average Baby and Your Baby scales. The second contact occurred four weeks postpartum at which time the NPI II consisting of the same Average Baby and Your Baby scales was mailed to each mother and returned by mail. In addition, each mother was contacted by telephone at the time the NPI II was mailed. Eighty percent of the mothers in both groups returned the NPI II forms. Precautions were taken to assure anonymity of all subjects. 


\section{Results: Patterns, Statistics}

It was hypothesized that mothers experiencing a rooming-in pattern of contact with their infants would exhibit a higher score on the NPI than mothers experiencing a traditional pattern of infant contact at a) two days postpartum and b) four weeks postpartum. The NPI scores obtained at both first and second contact with the mothers were compared using the student $t$ statistic. Although both groups of mothers did rate their babies as better than average, the differences between the two groups were not significant at either observation; thus the hypotheses were not supported (see Table 1).

A comparison was made on the responses of the two groups on items on the GIQ in order to test whether the samples were drawn from demographically similar populations. Using the student $\mathbf{t}$ statistic, no significant differences were found between the two groups (see Table 2). No statistical comparison was made of the mothers' occupational levels due to the small number of responses to that item from each group.

Chi's square analysis were done to determine between group differences on the attributive variables of attendance at prenatal classes, type of feeding, whether mother had natural childbirth, presence of the father at the delivery, preference for the previous experience with rooming-in. Significant differences between the rooming-in group and the traditional group were found on questions related to breast feeding, prior preference for rooming-in and prior experience with rooming-in (see Table 3).

Comparisons were also made of the responses of the two groups on individual NPI items at both observations using the Hotelling's T-square followed by individual student $t$ statistics. The results of the Hotelling's T-square were not significant at either observation.
Table 1

\begin{tabular}{|c|c|c|c|c|c|c|}
\hline \multicolumn{7}{|c|}{$\begin{array}{l}\text { Neonatal Perception Inventory Scores of Mothers in } \\
\text { Traditional and Rooming-in Hospital Settings }\end{array}$} \\
\hline Observation & $\begin{array}{l}\text { Mean } \\
\text { Scores } \\
\text { of } \\
\text { Mothers } \\
\text { with } \\
\text { Rooming- } \\
\text { in }\end{array}$ & $\mathbf{n}$ & $\begin{array}{l}\text { Mean } \\
\text { Scores } \\
\text { of } \\
\text { Mothers } \\
\text { with } \\
\text { Tradi- } \\
\text { tional }\end{array}$ & $\mathbf{n}$ & $\mathbf{t}$ & Sig. \\
\hline $\begin{array}{c}\text { NPI ll } \\
\text { NPI ll }\end{array}$ & $\begin{array}{l}1.85 \\
2.42\end{array}$ & $\begin{array}{l}46 \\
38\end{array}$ & $\begin{array}{l}1.71 \\
2.36\end{array}$ & 35 & $\begin{array}{r}1.34 \\
814\end{array}$ & n.s. \\
\hline \multicolumn{7}{|c|}{ a Administered 2 days postpartum. } \\
\hline
\end{tabular}

Table 2

\begin{tabular}{|c|c|c|c|c|}
\hline \multirow[b]{2}{*}{$\begin{array}{l}\text { Demographic } \\
\text { Variables }\end{array}$} & \multicolumn{3}{|c|}{$\begin{array}{l}\text { Demographic Description of Mothers by } \\
\text { Type of Hospital Setting }\end{array}$} & \multirow[b]{2}{*}{ Sig } \\
\hline & $\begin{array}{l}\text { Mothers } \\
\text { in } \\
\text { Rooming-in } \\
\text { Settings(46) }\end{array}$ & $\begin{array}{l}\text { Mothers } \\
\text { in } \\
\text { Traditional } \\
\text { Settings (35) }\end{array}$ & $t$ & \\
\hline Age of mother & $\begin{array}{l}24.5 \\
\text { years }\end{array}$ & $\begin{array}{l}23.89 \\
\text { years }\end{array}$ & .732 & n.s. \\
\hline $\begin{array}{l}\text { No. of } \\
\text { pregnancies }\end{array}$ & 2.15 & 1.94 & .765 & n.s. \\
\hline $\begin{array}{l}\text { No. of living } \\
\text { children }\end{array}$ & 1.80 & 1.82 & .100 & n.s. \\
\hline $\begin{array}{l}\text { Years of } \\
\text { education- } \\
\text { mother }\end{array}$ & 12.67 & 12.83 & .346 & n.s. \\
\hline $\begin{array}{l}\text { Years of } \\
\text { education- } \\
\text { father }\end{array}$ & 13.27 & 12.49 & 1.54 & n.s. \\
\hline
\end{tabular}


Table 3

\begin{tabular}{|c|c|c|c|c|}
\hline \multicolumn{5}{|c|}{$\begin{array}{l}\text { Comparison of Mothers in Rooming-in } \\
\text { and Traditional } \\
\text { Hospital Situations on Delivery and } \\
\text { Child Care Experiences }\end{array}$} \\
\hline $\begin{array}{l}\text { Delivery and } \\
\text { Child Care } \\
\text { Experiences }\end{array}$ & $\begin{array}{l}\text { Mothers } \\
\text { in } \\
\text { Rooming-in } \\
\text { Settings a }\end{array}$ & $\begin{array}{l}\text { Mothers } \\
\text { in } \\
\text { Traditional } \\
\text { Settings b }\end{array}$ & $\begin{array}{l}\text { Chi } \\
\text { Square }\end{array}$ & Sig. \\
\hline Breast feeding & $56.5 \%$ & $34.2 \%$ & 3.95 & $p \triangleleft .05$ \\
\hline $\begin{array}{l}\text { Natural } \\
\text { childbirth }\end{array}$ & $34.8 \%$ & $51.4 \%$ & 2.12 & n.s. \\
\hline $\begin{array}{l}\text { Husband } \\
\text { at delivery }\end{array}$ & $67.4 \%$ & $51.4 \%$ & 2.07 & n.s. \\
\hline $\begin{array}{l}\text { Prior } \\
\text { preference for } \\
\text { rooming-in }\end{array}$ & $50 \%$ & $22.9 \%$ & 5.99 & $p<.02$ \\
\hline $\begin{array}{l}\text { Prior } \\
\text { experience } \\
\text { with } \\
\text { rooming-in }\end{array}$ & $37.5 \%$ & $3.7 \%$ & 9.74 & $p \triangleleft .01$ \\
\hline $\begin{array}{l}\text { Number of } \\
\text { primiparae } \\
a_{n}=46 \\
b_{n}=35\end{array}$ & $37.9 \%$ & $37.1 \%$ & & n.s. \\
\hline
\end{tabular}

However, the student t revealed significant differences on three items of the NPI administered at the first observation. The mothers in the rooming-in setting expected the average baby to have less difficulty with bowel movements than did the mothers in the traditional setting (p. 1.05). Mothers in the rooming-in setting expressed the expectation that their babies would have less difficulty with feeding than did the mothers in the traditional setting ( $p .4$ .01 ); and the mothers in the rooming-in setting expressed the expectation that their babies would have less difficulty with bowel movements than did the mothers in the traditional setting ( $\mathrm{p}$. .02). The NPI administered at the fourweek observation period revealed no significant differences between the two groups on any individual items.

Using individual student t statistic, additional analyses were done to test the differences of scores achieved on individual items of the NPI as related to responses on the GIQ. Neither NPI score was found to be significantly related to parity, age of the mother, or the educational or occupational level of either parent. However, mothers who had attended five or more prenatal classes were found to express a more positive perception of their babies than did mothers who attended two or less prenatal classes (p. 4.05$)$. Also signiticant differences were found at both observations between mothers having natural childbirth and those not, with the mothers having natural childbirth expressing a significantly more positive perception of their infants (p. - 4.02) at the first observation and $(p .-05)$ at the second observation). No significant differences were found on the NPI scores at either observation between mothers bottle feeding and mothers breast feeding their infants, and there were no differences between mothers expressing a prior preference for rooming-in.

The two groups were combined and student $t$ statistic comparisons made of 
primiparae and multiparae on the NPI items obtained on the first observation. All primiparae's scores, specifically in the rooming-in group, expressed an expectation of more difficulty with feeding their infants than did multiparae (p. $05)$. No significant differences were found between multiparae and primiparae on the second observation NPI scores.

\section{Discussion}

The hypothesis that rooming-in mothers would score significantly higher on the NPI than mothers having a traditional pattern of infant care was not supported. Several factors may have contributed to the findings. One such factor was the unavailability of data relative to the actual amount of mother-infant contact in the rooming-in setting. Although it was possible for mothers to have their babies with them 24 hours a day, records did not indicate the exact number of hours during which the infant was with the mother. In addition, the investigators were not able to determine the nature of contact between mother and infant while the baby was in the room. It is possible, therefore, that some mothers in the rooming-in sample may have had no more contact with their infants than did mothers in the traditional group.

Another factor which may have contributed to the lack of significant findings is the unavailability of data concerning the amount of contact between mother and infant in the delivery and recovery rooms. In both groups some mothers may have had an opportunity to hold and/or feed their infants during that period, a time which some studies indicate may be of importance in the development of the mother-infant relationship. Notwithstanding, several interesting findings did emerge. On the first NPI mothers in the rooming-in group expressed a more positive perception of their babies on each in- dividual item than did mothers in the traditional group. Although the differences between the two groups was not statistically significant for any item, the direction of differences was consistent across the scale. This finding did not hold true, however, on the NPI administered four weeks postpartum. At its second observation no item responses were significantly different, and the direction of the difference between the groups varied from item to item. This may suggest that, although the experience of rooming-in has not been shown to produce a long-term change in the mother's perception of her infant, it may be that rooming-in produces more positive attitudes in mothers during the sensitive postpartum period. This may be clinically important because mothers who are having more positive feelings about their experiences will probably have more energy to invest in their relationship with their babies.

Mothers in the rooming-in setting expressed the expectation of experiencing less difficulty in feeding their babies and with their babies' bowel movements than did mothers in the traditional setting. These mothers were actually more involved in caring for their babies and, therefore, may have had more opportunity to work through their fears about their own ability to provide adequate care than mothers who had not had the opportunity for prolonged contact. Similarly, mothers who attended five or more prenatal classes in both groups expressed a more positive perception of their babies than mothers who attended two or less. Both findings suggest that mothers who have more knowledge about babies in general and their own babies specifically were able to view their babies more positively than mothers with less knowledge. This explanation agrees with theorists' statements that acquisition of new knowledge and increasing one's repertoire of responses in new life situations is essential in maintaining emotional health (Broussard, 1976; Caplan, 1955; Cyr and Wattenberg, 1957). Prenatal classes and caring for the infant in a rooming-in setting may provide the mother the opportunity to acquire knowledge and confidence in her new role as well as enhance her relationship with her baby.

The finding of significantly more positive perceptions of their infants reported by mothers having had natural childbirth compared to those who did not may again be related to the amount of prenatal preparation given to most of these mothers. It is possible, however, that other factors, such as the mother's desire for the baby and involvement of the father, may have affected the outcome.

Comparing Primiparae and Multiparae revealed that primiparae in both groups expressed an expectation of more difficulties in feeding their babies than did multiparae and that primiparae involved in caring for their babies for the first time experience more anxiety about that care than do primiparae who have not yet had the responsibility of their infant's care. It may be particularly significant, then, for primiparae to have the opportunity of caring for their infants while in the hospital where support and supervision is available.

In this study a significantly higher number of mothers in the rooming-in group breast fed their babies as compared with the traditional group. This finding supports McBryde's observation (1951) that compulsory rooming-in resulted in an increased percentage of breast feeding mothers. Other contributing factors may be differences in community norms and attitudes of both medical and nursing staff.

\section{Limitations of the Study}

One limitation of the study was the lack of a plan to collect data regarding the cultural composition of the two 
groups. In retrospect, we perceived that the rooming-in group had greater ethnic variability than the traditional group. Further research is necessary to document the effect of variable of ethnicity.

One variable which the investigators were unable to control was the possibility that mothers preselected their hospitals in order to have a rooming-in experience with their babies. This contingency makes it conceivable that the groups differed in their desire for increased postpartum contact with their babies. This possibility was supported by the fact that the rooming-in and traditional groups were found to differ significantly on items related to prior experience with, and preference for, rooming-in. It should be noted, however, that the two rooming-in hospitals are the major maternity units in the area and have many of the same physicians on staff. This may have reduced the effect of mothers selecting their doctors or hospitals on the basis of postpartum infant care policies. It was not possible to determine the effects, if any, of differences in unit size, staffing patterns, or amount and kind of nursepatient interactions.

A final major limitation of the study was the inability of the investigators to control or to determine the amount of actual contact the mothers in the rooming-in group experienced with their babies.

\section{Summary}

Findings of this study include evidence of the relationship between mothers having had a rooming-in hospital experience and a higher incidence of breast feeding. There is also evidence that rooming-in mothers in the immediate postpartum period expected less difficulty with some aspects of their infant's care. Both these findings indicate that there are some positive outcomes of rooming-in. Future study might explore the amount of contact actually experienced by mothers and the kinds of activities in which they are involved with their babies in rooming-in settings.

A finding of particular clinical consequence was that mothers having had five or more prenatal classes and who had natural childbirth had a more positive perception of their infants. Another interesting and expected outcome was that multiparae expected fewer difficulties with the care of their babies than did primiparae. This finding, as well as the positive effect of prenatal classes, may be a result of the mothers' ability to practice the mother role.

\section{REFERENCES}

Barnett, C.R., Lieberman, P.H., Grobstein, R. \& Klaus, M.H. "Neonatal separation: the maternal side of the interactional deprivation." Pediatrics, 1970. 45, 197.205.

Baumann, E. "The visiting nurse views rooming-in." Public Health Nursing, 1950, 42, 263-266

Broussard, E.R. "Longitudinal study of first-borns aged 10/11 years." Paper presented at the meeting of the American Psychiatric Association. Anaheim, California. May 8, 1975

Broussard. E.R. "Evaluation of televised anticipatory guidance to primiparae." Community Mental Health Journal, 1976. 1, 2 (2). 203-210

Broussard, E.R. \& Hartner, M.S. "Maternal perception of the neonate as related to development." Child Psychiatry and Human Development, 1970, 1, (10)

Caplan, G. Emotional Problems of Early Childhood. New York: Basic Books, Inc., 1955.

Cyr, F.E. \& Wattenberg, S.H. "Social work in a preventive program of maternal and child health." Soclal Work, 1957, 2(3)

Greenberg, M., Rosenberg. I. \& Lind. J. "First mothers rooming-in with their newborns: its impact upon the mother." American Journal of Orthopsychiatry, $1973,43,(5), 783-788$.

Jackson, E. "Should mother and baby room together?" American Journal of Nursing, 1946, 46 (17), 17-19

Jackson, E. "General reactions of mothers and nurses to rooming-in" American Journal of Public Health, 1948, 38, 689-695.
Jackson, E., Olmsted, R.W., Foord, A., Thoms, H. \& Hyder, K. "A hospital rooming-in unit for four newborn infants and their mothers." Pediatrics, $1948,1,28-43$

Klaus, M.H., Jerauld, R., Kreger, N.C., McAlpine, W., Steffa, M. \& Kennell, J.H. "Maternal attachment: importance of the first postpartum days." New England Journal of Medicine, 1972, 286 (9), 460-463

Klaus, M.H. \& KennelI, J.H. "Mothers separated from their newborn infants." Pediatric Clinics of North America, 1970, 17, 1015-1035.

Klaus, M.H. \& Kennell, J.H. Maternal-infant bonding. St. Louis: C.V. Mosby, 1976.

Klaus, M.H., Kennell, J.H., Plumb, N. \& Zuehlke, S. "Human maternal behavior at the first contact with her young." Pedlatrics, 1970, 46(190), $187-192$

Klopfer, P.H. "Mother love: what turns it on?" American Scientist, 1971, 59, 404-407.

Leifer, A.D., Lieberman, P.H., Barnett, C.R. \& Williams, J.A. "Effects of mother-infant separation on maternal attachment behavior." Child Development, 1972, 43, 1203-1218.

McBryde, A. "Compulsory rooming-in in the ward and private newbom service at Duke Hospital." Journal of the American Medical Association, 1951, 145 (9), 625-628.

Montgomery, T.L., Steward, R.E. \& Shenk, E.P. “Observations on the rooming-in program of baby with mother in ward and private service." American Journal of Obstetrics and Gynecology, 1949, 57, (1), 176-184.

Parks, J., McLendon, P.A. \& Kelley, M. "Optional nursery facilities for the care of mothers and newbom infants." American Journal of Obstetrics and Gynecology, 1953, 66 (5), 938-951.

Ringholtz, S. \& Morris, M. "A test of some assumptions about rooming-in." Nursing Research, 1961. 10 (4), 196-199

Rosenblatt, J.S. "The development of maternal responsiveness in the rat." American Journal of Orthopsychiatry, 1969,39 (1), 36-55

Shea, N., Klatskin, E.H., \& Jackson, E.B. "Home adjustment of rooming-in and non-rooming-in mothers." American Journal of Nursing, 1952, 52 (1), 65-67.

Songstegard, L. \& Egan, E. "Family-centered nursing makes a difference." American Journal of Maternal Child Nursing, 1976, (1) (4), 249-254.

Terkel, J. \& Rosenblatt, J.S. "Hormonal factors underlying maternal behaviors at parturition: cross transfusion between freely moving rats." Journal of Comparative Physiologic Psychology, $1972,80,365-371$

Warner, W.L. Social Class in America. New York: Harper and Row, 1960.

Zarrow, M.X., Gandelman, R. \& Rosenberg, V. "Prolac tin: is it an essential hormone for maternal be havior in the mammal?" Hormones Behavior. $1971,2,343-354$. 